\title{
Spatially optimised tree plantings to minimise urban heat
}

\author{
$\underline{\text { Oswald Marinoni }}^{\text {a }}$, Michael Battaglia ${ }^{\text {b }}$, Matthew Beaty ${ }^{c}$ \\ ${ }^{a}$ CSIRO Land and Water, ${ }^{b}$ CSIRO Agriculture and Food, ${ }^{c}$ University of New South Wales, Canberra \\ Email: Oswald.marinoni@,csiro
}

\begin{abstract}
There is a notable increase of "Greener City" strategies which indicates a re-discovery of the many benefits urban greenspace provides. The planning of urban green space, particularly urban forests, on a relatively large scale in a very complex multi layered urban environment is however a challenging task. Multiple benefits must be simultaneously evaluated and traded-off. Here, we present a feasibility concept which combines spatial analysis and tree architecture with concepts from operations research to spatially target planting locations. We demonstrate the concept in a highly simplified approach to reduce urban heat. Because of its prototype character and its simplified assumptions, particularly around local heat balances, we do not advocate an application of the method in current planning processes but stress the need to integrate a more sophisticated heat balance model. Though urban trees provide many other benefits such as visual amenity, recreational and health benefits and constraints such as root impacts on infrastructure exist these are presently excluded from the initial model and may be incorporated in subsequent model extensions.
\end{abstract}

Keywords: $\quad$ Urban heat island effect, urban forest, allometry, spatial optimization 


\section{INTRODUCTION}

Recent studies have outlined the multiple benefits urban green space and in particular urban forests provide. These include cooling effects, energy savings, air quality benefits as well as aesthetic, recreational and health benefits (Brown et al., 2013; Kirnbauer and Baetz, 2014; McPherson et al., 2011) and city councils all over the world have started to promote and implement the concept of urban forestry (City of Melbourne, 2012; City of Sydney, 2013; City of Vancouver, 2014). While most urban forestry strategies set tree coverage targets for the next 15 to 35 years, no clear process is outlined that describes where these millions of new trees (and what species) should be planted to maximize the benefits from tree establishment. The benefit targeted here is the cooling effect provided by trees. Trees can help reduce the urban heat island effect (UHI) and addressing this is becoming ever more pressing as the frequency of extreme high temperature is on the rise. Trees contribute to the cooling of their surrounding environment through the provision of shade, reflectance of sunlight and through evapotranspiration (Doik and Hutchins, 2013). Generally, vegetation is considered to be cost-effective in altering the amounts of heat energy in urban areas (Norton et al., 2013).

The extent to which trees provide cooling through shade and evapotranspiration depends on the tree species, the age of a tree and, ultimately, the amount of leaf area that is available. Various studies have analysed the impact of urban green cover on temperatures and micro-climate (Petralli et al., 2014; Qin et al., 2014) and there is evidence that air temperatures beneath both individual trees and clusters of trees are lower than temperatures in an open area (Bowler et al., 2010). However, individual tree species vary in their ability to reduce air temperature as a result of differences in tree size and tree canopy characteristics that in turn affect the penetration of solar radiation. While there is agreement that urban areas fundamentally alter local energy balances, there is still debate on how the spatial configuration of trees influences the UHI effect (Debbage and Shepherd, 2015). Tools exist that help to better plan and manage urban forests. Kirnbauer et al. (2009) presented the freely available TreeModules. The iTree (USDA, 2006) tools suite, perhaps the most comprehensive and prominent model, is used to monitor existing urban green cover, provide benefit metrics and tangibles for ecosystem services of green cover for entire urban forests or individual trees. The iTreeDesign application even allows for an assessment at a parcel level; trees can be selected and placed and benefits including changes to home energy use can be estimated. There remains a need, however, for a means to evaluate the spatial arrangement of urban forests within identified opportunity areas such that individual benefits are optimised and trade-offs between benefits can be analysed. This is a topical area of research and more advanced concepts that integrate tree planting scenarios and trade-offs of ecosystem services were presented just recently (Bodnaruk et al., 2017). Here, a prototype concept is presented which suggests an integration of prognostic tree architecture features and related benefit performance in time.

\section{METHODS AND DATA}

The study area is located in a key growth area in Melbourne's south west (Figure 1). There are 3 planting sites with a total area of $694,000 \mathrm{~m}^{2}(=69.4 \mathrm{ha})$. The site being referred to in this paper is the central site \#2.
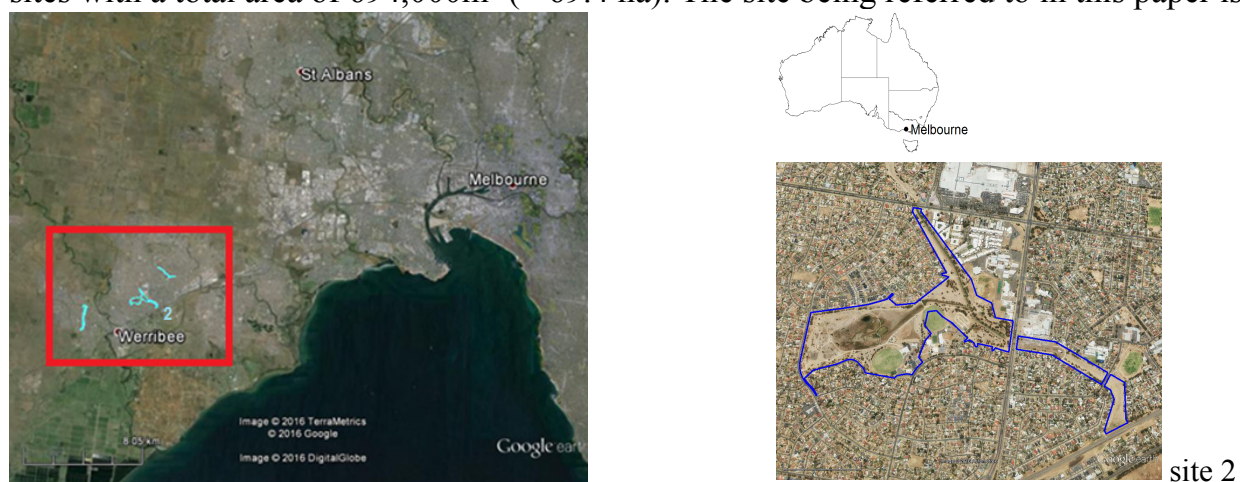

Figure 1. Location of site 2 within Wyndham Council near Werribee. Images taken from Google Earth.

\subsection{Heat maps}

Thermal remote sensing was used to characterize variations in temperature across the study area. Land surface temperatures were derived from the thermal band (Band 6) from a cloud-free Landsat 5 Thematic Mapper (TM) image collected at 10:33 AM local time on 29 March 2015. The measurements were thus taken in the late morning and measured values were therefore not truly representative of daily peak temperatures. To demonstrate the approach and model without relying upon further temperature measurements, the late 
morning measurements were used as a proxy for the peak temperatures. With air temperature reductions being in the focus of the subsequently presented model it is important to note that in absence of air temperature data the simplified assumption was made that areas having hotter surfaces will have higher air temperatures also. The pixel resolution was $30 \mathrm{~m}$.

\subsection{Tree species to be planted}

Council has a variety of species considered suitable for planting in the area. A portfolio of tree species including their approximate proportions was provided by the Council tree planner. Each species provides varied attributes as described in Table 1.

Table 1. Tree species to be planted.

$\begin{array}{ll}\# & \text { Species } \\ 1 & \text { Eucalyptus camaldulensis } \\ & \\ 2 & \text { Eucalyptus tricarpa } \\ 3 & \text { Acacia implexa } \\ 4 & \text { Allocasuarina verticillata }\end{array}$

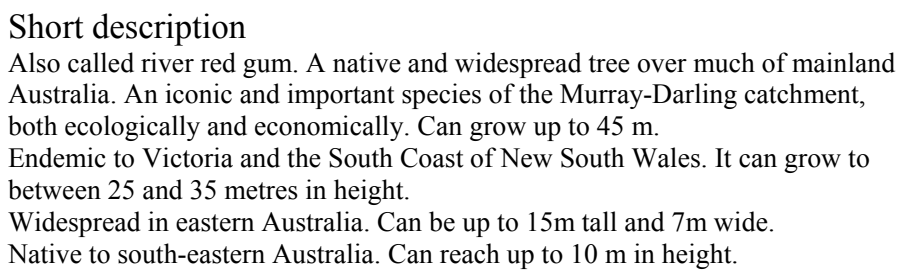

The chosen tree species will not be planted in equal proportion. Across the three sites, the two Eucalyptus $s p p$. will each represent about $10 \%$ of all trees whereas the $A$. implexa and $A$. verticillata will each represent $40 \%$. The total number of trees to be planted depends on the available plantable area and the expected canopy diameter of the matured tree species which will be inferred using tree allometry (section 2.3).

\subsection{Estimation of tree features in time}

Communities and planners are interested in the temperature reduction performance that can be expected once trees are fully grown. Young trees which are planted today will enlarge over time and the benefits they deliver will change accordingly. This means that the developed model will require the ability to predict the performance of tree species along a variety of tree features in time. To do this one can take advantage of plant allometry. Allometry captures the relative change of one plant dimension in relation to the relative change of a second plant dimension (Pretzsch et al., 2015). Here, the stem diameter - crown radius allometry is used to infer the crown radius from the stem diameter. The stem diameter in turn will be estimated from the age of a tree. The ability of a tree species to filter solar radiation will be estimated via the Leaf Area Index (LAI) which can be inferred for a tree species from the age as well. Once the LAI is known the BeerLambert law is applied to estimate the amount of solar radiation that is absorbed. The Beer-Lambert law, sometimes called Beer's law, is (Monteith and Unsworth, 2013):

$\tau=e^{-k \cdot L A I}$

where

$k$ : attenuation coefficient (specific to species)

$L A I$ : Leaf area index

$\tau$ : amount of solar radiation passing through canopy ( $=\mathrm{L}$ parameter $)$

\subsection{Estimation of temperature reduction}

The objective of the presented study was to optimize the spatial locations of trees and tree species so that heat reduction caused by the trees was maximized. To do this in a qualitative way it would be sufficient to use the LAI: trees having a larger LAI will reduce temperature more than the same number of trees that have a lower LAI. Any spatial optimization would have to attempt to maximize the area coverage of higher LAIs in areas of higher temperatures. This does however not suffice to provide an estimate of the temperature reduction that can be achieved. At this initial stage of the model development a simple and generic approach was required which would be flexible enough to be modified for other species and that captured a heat reduction response with an accuracy that was relevant for the model task. The approach used was suggested by Georgi and Zafiriadis (2006) who fitted an exponential model which captures the relationship between the solar radiation that passes through the canopy and air temperature reduction to empirical observations. The approach has no explicit component which allowed for an inference of the contribution of a tree species' rate of evapotranspiration to air temperature reduction. The percentage of air temperature reduction $\Delta T$ is given by

$$
\Delta T=a \cdot e^{-b L}
$$


where

$\Delta T$ is the temperature $\left({ }^{\circ} \mathrm{C}\right)$ reduction of the air in percent

$L$ is the percentage of light that passes through the canopy. The value of $L$ depends upon the tree species

$a$ and $b$ are parameters which depend on the climatic conditions of the study area

With no microclimate measurements for the study area available, the climate related values for parameters $a$ and $b$ are not known. In consultation with researchers who have studied the change of the microclimate under trees in Melbourne a value of 4 was chosen for parameter $a$ (Coutts et al., 2016). For $b$ a value of 0.2 was applied as it captures a more gradual decrease of temperature reduction with an increase of solar radiation passing through a tree's canopy.

\subsection{Model assumptions and limitations}

The developed model represents an abstract representation of a complex biophysical system. As such it is subject to a range of assumptions and simplifications which are listed in Table 2.

Table 2. Assumptions the presented model is based upon.

\begin{tabular}{|c|c|c|}
\hline \# & Assumption/constraint & Comment/explanation(s) \\
\hline 1. & $\begin{array}{l}\text { The planting of a tree will, as a tree matures, lead to a reduction of } \\
\text { air and surface temperatures }\end{array}$ & $\begin{array}{l}\text { Fundamental assumption backed by findings in the scientific } \\
\text { literature and every day experience }\end{array}$ \\
\hline 2. & $\begin{array}{l}\text { The area where the temperature will be reduced is equal to the } \\
\text { canopy area }\end{array}$ & \\
\hline 3. & $\begin{array}{l}\text { The temperature reduction under a tree depends on the canopy } \\
\text { thickness (the thicker the canopy (or the higher the LAI) the } \\
\text { higher the temperature reduction) }\end{array}$ & sinen \\
\hline 4. & $\begin{array}{l}\text { The canopies of trees planted in the model are circular and must } \\
\text { not intersect }\end{array}$ & \\
\hline 5. & $\begin{array}{l}\text { The total canopy area must not exceed the plantable area (=pixel } \\
\text { area) }\end{array}$ & \\
\hline 6. & $\begin{array}{l}\text { The fact that different tree species grow to different heights is } \\
\text { neglected }\end{array}$ & (Forrester and Albrecht, 2014) \\
\hline 7. & $\begin{array}{l}\text { Trees are above soil surfaces. It is assumed that no heat is re- } \\
\text { radiated back from the soil surface }\end{array}$ & \\
\hline 8. & $\begin{array}{l}\text { Any further thermal interactions between and beyond individual } \\
\text { trees or tree assemblies, potentially driven by convection, are not } \\
\text { considered }\end{array}$ & \\
\hline
\end{tabular}

Based on these limitations it is obvious that the provision of accurate estimates of temperature reduction will require the integration of a more sophisticated urban heat balance model.

\subsection{Spatial optimization}

To optimize the spatial distribution of trees Simulated Annealing (SA) was used. SA introduced by Metropolis et al. (1953) and discussed by Kirkpatrick et al. (1983) in the context of combinatorial optimization problems. The basic idea is to continuously perturb a system to produce more favourable perturbations while gradually decreasing the energy level (the temperature) of the modelled system, thus mimicking the process of a cooling material. The analogy to the distribution of trees is that the energy level is replaced by an objective function which measures the temperature reduction performance of a distinct spatial distribution of trees. A perturbation to the system includes the swapping of trees or shifting one or more trees to other locations. If a new spatial distribution of trees leads to an overall performance improvement it is kept in memory and the next perturbation is induced. 


\section{ANALYSIS}

The total number of trees that will fit in the target area was determined so that the total area of the canopies of all trees was just below the target area of $690,000 \mathrm{~m}^{2}$ which represents the total plantable area. The plantable area of site 2 is about $475,000 \mathrm{~m}^{2}$. The expected canopy areas per tree are assumed to be circular and based on the predicted canopy radius when fully grown and were computed with

Canopy area $=\pi \cdot(d / 2)^{2}$

When mature an area of $176.71 \mathrm{~m}^{2}$ was determined for the eucalypts, for A. implexa and A. verticillata an area of $28.27 \mathrm{~m}^{2}$ was estimated. These canopy areas and the plantable area led to a figure of about 9,000 trees for site 2 .

Table 3. Tree parameters this analysis is based upon.

\begin{tabular}{|c|c|c|c|c|}
\hline Species & Share $(\%)$ & $\begin{array}{c}\text { Estimated crown } \\
\text { diameter d }(\mathrm{m}) \\
\text { Fully grown }\end{array}$ & $\begin{array}{l}\text { Estimated crown diameter } \\
\qquad \mathrm{d}_{20}(\mathrm{~m}) \\
\text { after } 20 \text { years }\end{array}$ & $\mathrm{L}$ \\
\hline E. camaldulensis & 10 & 15 & 9.5 & 13.53 \\
\hline E. tricarpa & 10 & 15 & 9.5 & 13.53 \\
\hline A. implexa & 40 & 6 & 3 & 30.12 \\
\hline A. verticillata & 40 & 6 & 5 & 67.03 \\
\hline Remarks: & $\begin{array}{l}\text { Shares provided by } \\
\text { council tree } \\
\text { planner }\end{array}$ & $\begin{array}{l}\text { Used to estimate the } \\
\text { number of trees that will } \\
\text { fit in the target area }\end{array}$ & $\begin{array}{l}20 \text { years (240 months) is the target time frame } \\
\text { (diameters estimated using allometric } \\
\text { relationships from Pretzsch et al. (2015), see } \\
\text { section 2.3) }\end{array}$ & $\begin{array}{l}\text { Percentage of incident solar } \\
\text { radiation that passes through } \\
\text { the canopy when the sun is } \\
\text { directly overhead }\end{array}$ \\
\hline
\end{tabular}

The solar radiation that passes through a tree's canopy depends upon the leaf area indexes (LAI) and the attenuation coefficient $k$. The LAI's as well as the attenuation coefficients $k$ were estimated:

\begin{tabular}{lccc}
\hline \hline Species & $\mathrm{k}$ & LAI & L (section 2.1) using Beer's law (section 2.3) \\
\hline \hline Eucalyptus spp. & 0.5 & 4 & $13.53=\left(e^{-0.5 \cdot 4}\right) \times 100$ \\
A. verticillata & 0.4 & 1 & 67.03 \\
A. implexa & 0.6 & 2 & 30.12 \\
\hline \hline
\end{tabular}

In case of Eucalyptus spp. a value of 13.53 for $L$ means that about $13.5 \%$ of the solar radiation passes through the canopy.

\section{RESULTS FOR PLANTING SITE 2}

Site 2 is the largest site with the highest number of trees. Temperatures are higher in the western part. In its optimised solution, the model suggests to plant trees with a higher LAI ( $\rightarrow$ eucalypts) in these areas (Figure 2 ).
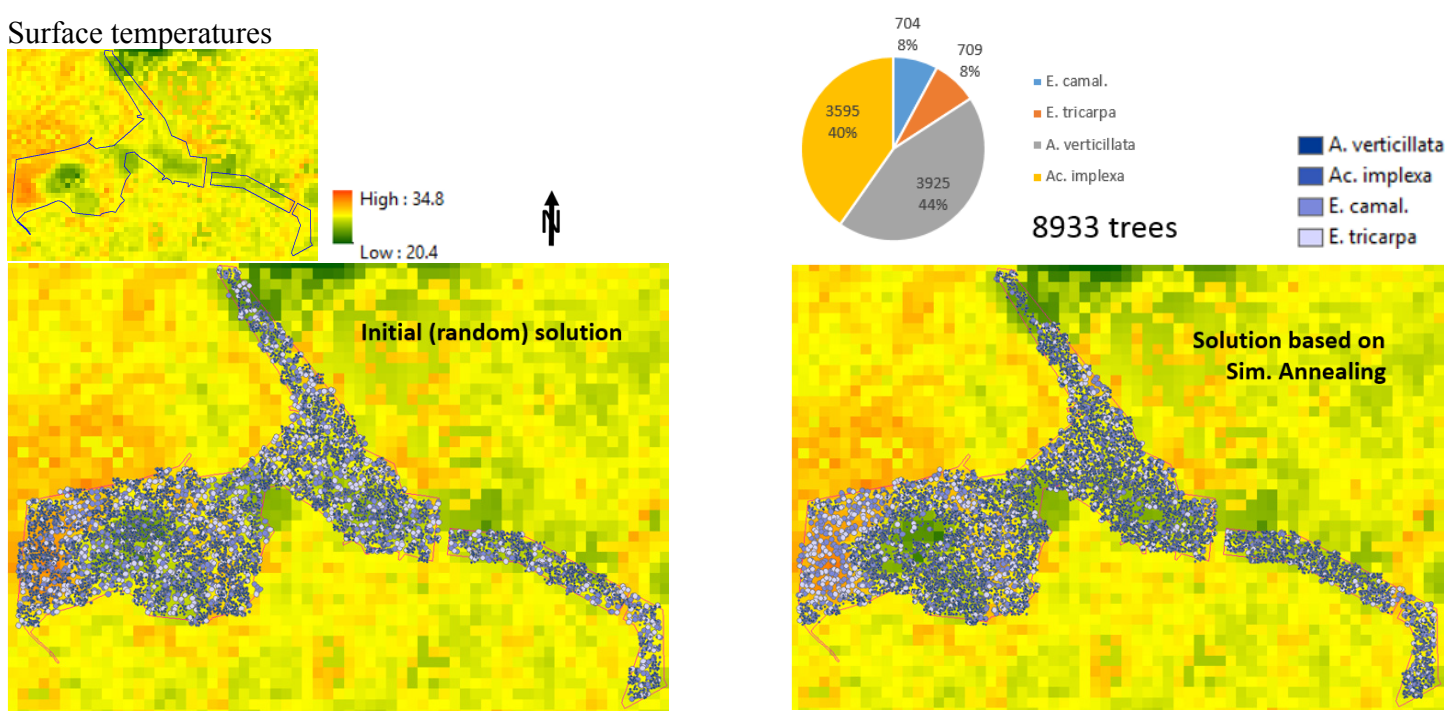

Figure 2. Suggested solution for the new tree plantings at site 2.

In its solution, the model left some pixels without tree cover (see central area of the western part). These areas are amongst the coolest pixels in the study area. Planting trees there would locally reduce temperature 
as well but in terms of the objective to reduce overall temperature it is more efficient to plant trees at hotter locations. East to West distance $\sim 1.9 \mathrm{~km}$. Note that a set of entirely randomly distributed trees (random initial solution) will lead to a temperature reduction also. The optimised solution however led to a further average temperature reduction per pixel of $4.7 \%$.

\section{Estimates for reduced temperatures}

The map shown in Figure 3 shows the estimated air temperature reduction assuming that all trees will be mature, that is, have reached their full LAI and full canopy radius (as provided in section 3 ).
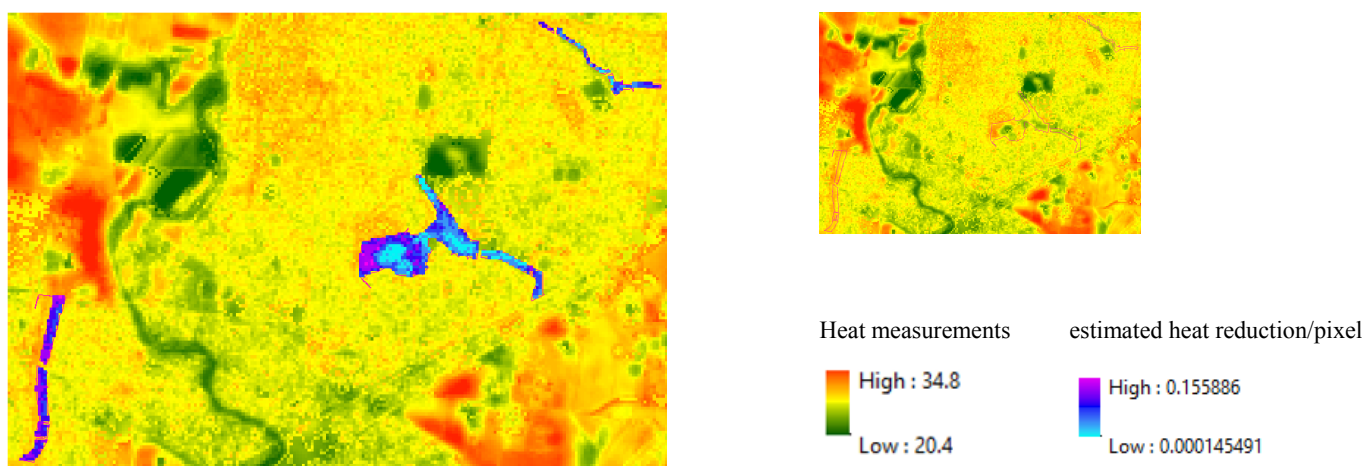

Figure 3. Estimated temperature reduction per pixel assuming fully grown trees. All values in $\left({ }^{\circ} \mathrm{C}\right)$.

\section{DISCUSSION AND CONCLUSIONS}

We presented a feasibility study of a semi-quantitative model which, based largely upon the leaf area index, spatially optimizes the locations of tree plantings such that air temperature reduction is maximized. At its current stage the model lacks an accurate heat balance component and temperature estimates are based on a set of highly simplified assumptions. We therefore do not advocate an application of the method in current planning processes and stress the need to integrate a more sophisticated heat balance model. We suggest a variety of further model improvements including but not limited to

1. Extending the model across more objectives, e.g. air cleaning benefits, aesthetic benefits and ecological benefits.

2. Inclusion of more complex spatial constraints. This would include all sorts of corridors and buffer zones around water pipes, gas pipes etc.

3. Inclusion of location specific biophysical parameters which favour/impede the growth of certain species.

4. There is a need to integrate a more explicit economic component which addresses the costs to plant, maintain and remove trees over a longer period in time.

5. Inclusion of tree mortality. Not all trees that are planted are going to survive. Some trees will die from having to compete with their neighbouring trees whereas others might die from some pests or disease, lack of water or other reasons.

\section{ACKNOWLEDGMENTS}

This project was funded by City West Water and co-funded by CSIRO Land and Water. Greatly acknowledged is also the support of Wyndham Council for the provision of the required datasets, tree species related advise, tree planning expertise and for organizing a field trip.

\section{REFERENCES}

Bodnaruk, E.W., Kroll, C.N., Yang, Y., Hirabayashi, S., Nowak, D.J., Endreny, T.A. (2017). Where to plant urban trees? A spatially explicit methodology to explore ecosystem service tradeoffs. Landscape and Urban Planning 157, 457-467.

Bowler, D.E., Buyung-Ali, L., Knight, T.M., Pullin, A.S. (2010). Urban greening to cool towns and cities: A systematic review of the empirical evidence. Landscape and Urban Planning 97, 147-155.

Brown, H., Katscherian, D., Carter, M., Spickett, J. (2013). Cool communities: Urban trees, climate and health, p. 37. 
City of Melbourne (2012). URBAN FOREST STRATEGY Making a great city greener 2012-2032. City of Melbourne, p. 67.

City of Sydney (2013). Urban Forest Strategy 2013. City of Sydney, Sydney, p. 80.

City of Vancouver (2014). City of Vancouver - Urban Forest Strategy, p. 59.

Coutts, A., Moore, C., Tapper, N., White, E. (2016). The microclimate and water use of an isolated tree in the dead centre of the city, 2nd Urban Tree Diversity Conference, Melbourne, Australia.

Debbage, N., Shepherd, J.M. (2015). The urban heat island effect and city contiguity. Computers, Environment and Urban Systems 54, 181-194.

Doik, K., Hutchins, T. (2013). Air temperature regulation by urban trees and green infrastructure. Forestry Commission, p. 10.

Forrester, D.I., Albrecht, A.T. (2014). Light absorption and light-use efficiency in mixtures of Abies alba and Picea abies along a productivity gradient. For Ecol Manage 328.

Georgi, N.J., Zafiriadis, K. (2006). The impact of park trees on microclimate in urban areas. Urban Ecosystems 9, 195-209.

Kirkpatrick, S., Gelatt, C.D., Vecchi, M.P. (1983). Optimization By Simulated Annealing. Science 220, 671680 .

Kirnbauer, M., Baetz, B. (2014). Prototype Decision-Support System for Designing and Costing Municipal Green Infrastructure. Journal of Urban Planning and Development 140.

Kirnbauer, M.C., Kenney, W.A., Churchill, C.J., Baetz, B.W. (2009). A prototype decision support system for sustainable urban tree planting programs. Urban Forestry \& Urban Greening 8, 3-19.

McPherson, E.G., Simpson, J.R., Xiao, Q., Wu, C. (2011). Million trees Los Angeles canopy cover and benefit assessment. Landscape and Urban Planning 99, 40-50.

Metropolis, N., Rosenbluth, A.W., Rosenbluth, M.N., Teller, A.H., Teller, E. (1953). Equation Of State Calculations By Fast Computing Machines. Journal of Chemical Physics 21, 1087-1092.

Monteith, J.L., Unsworth, M.H. (2013). Principles of Environmental Physics, 4th edition, 401 pp.

Norton, B., Bosomworth, K., Coutts, A., Williams, N., Livesley, S., Trundle, A., Harris, R., McEvoy, D. (2013). Planning for a cooler future: Green infrastructure to reduce urban heat, Climate Adaptation for Decision-makers. Victorian Centre for Climate Change Adaptation research (VCCCAR), Melbourne.

Petralli, M., Massetti, L., Brandani, G., Orlandini, S. (2014). Urban planning indicators: useful tools to measure the effect of urbanization and vegetation on summer air temperatures. International Journal of Climatology 34, 1236-1244.

Pretzsch, H., Biber, P., Uhl, E., Dahlhausen, J., Roetzer, T., Caldentey, J., Koike, T., van Con, T., Chavanne, A., Seifert, T., du Toit, B., Farnden, C., Pauleit, S. (2015). Crown size and growing space requirement of common tree species in urban centres, parks, and forests. Urban Forestry \& Urban Greening 14, 466-479.

Qin, Z., Li, Z., Cheng, F., Chen, J., Liang, B. (2014). Influence of canopy structural characteristics on cooling and humidifying effects of Populus tomentosa community on calm sunny summer days. Landscape and Urban Planning 127, 75-82.

USDA (2006). iTree. 